\title{
Enkulturasi Nilai Kebhinekaan untuk Menciptakan Guyub Rukun
}

\section{Prof. Dr. Hermanu Joebagio, M.Pd}

Kepala Pusat Studi Pengamalan Pancasila - LPPM UNS Kepala Program Studi Doktor Pendidikan Sejarah - Pascasarjana UNS hermanu.joebagio@gmail.com

\section{ENKULTURASI NILAI KEBHINEKAAN UNTUK MENCIPTAKAN GUYUB RUKUN}

PROF. DR. HERMANU JOEBAGIO, M.PD KEPALA PUSAT STUDI PENGAMALAN PANCASILA - LPPM UNS KEPALA PROGRAM STUDI DOKTOR PENDIDIKAN SEJARAH - PASCASARJANA UNS

\section{PERKEMBANGAN STRUKTUR SOSIAL MASYARAKAT NUSANTARA}

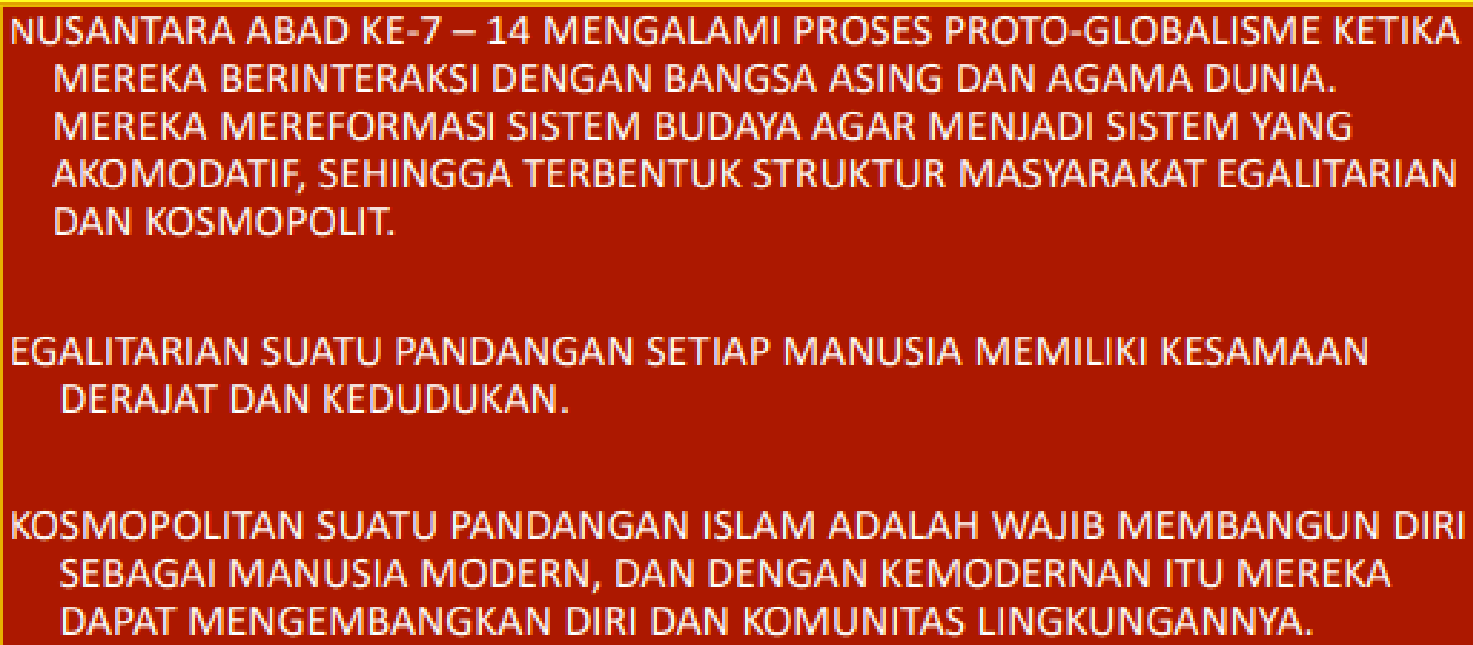

KOSMOPOLITAN SUATU PANDANGAN ISLAM ADALAH WAJIB MEMBANGUN DIRI SEBAGAI MANUSIA MODERN, DAN DENGAN KEMODERNAN ITU MEREKA DAPAT MENGEMBANGKAN DIRI DAN KOMUNITAS LINGKUNGANNYA.

Social, Humanities, and Education Studies (SHEs): Conference Series https://jurnal.uns.ac.id/shes

p-ISSN 2620-9284 e-ISSN 2620-9292

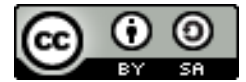

This work is licensed under a Creative Commons Attribution-ShareAlike 4.0 International License. 
BENCHMARK MASYARAKAT EGALITARIAN DAN KOSMOPOLIT ADALAH MENGARUSTAMAKAN KECERDASAN LINGKUNGAN SOSIAL MEREKA, AGAR BERGUNA MEMBANGUN BANGSA DAN NEGARA.

PENDAPAT SAMA DIKEMUKAKAN OLEH ROBERT A. DAHL (1995), BENCHMARK STRUKTUR SOSIAL YANG EGALITARIAN DAN KOSMOPOLIT ITU BERCIRIKAN PLURAL, DYNAMIC, DAN MODERN.

CIRI PLURAL, DYNAMIC, DAN MODERN MERUPAKAN SIFAT GIVEN BAGI BANGSA INDONESIA, KEMUDIAN MENJADI DASAR PEMIKIRAN DAN CITRA TERBAYANG PARA PENDIRI BANGSA DALAM SIDANG BPUPK (29 MEI - 1 JUNI 1945)

ISTILAH DAN PENGERTIAN BHINNEKA TUNGGAL IKA

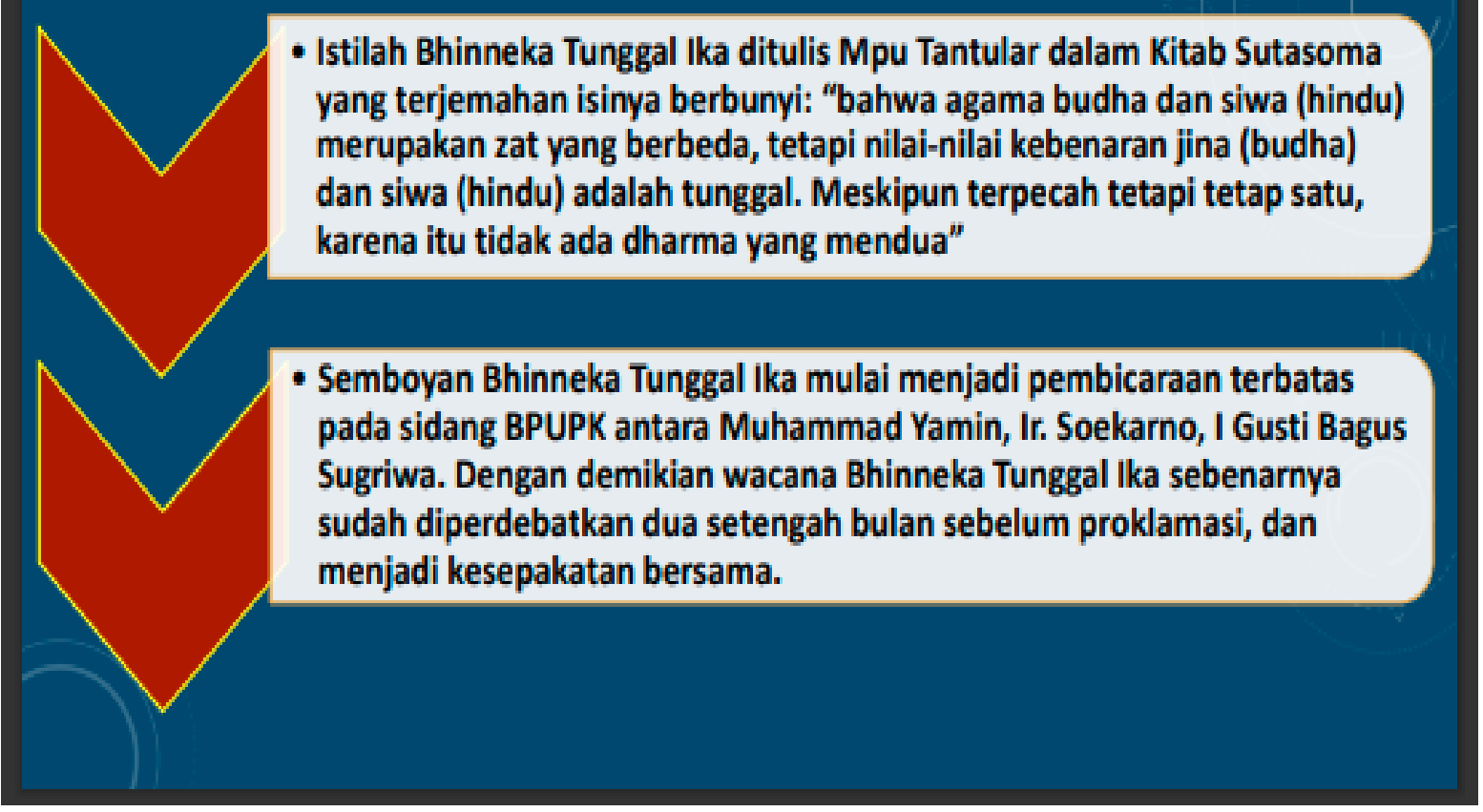




\section{LANUUTAN}

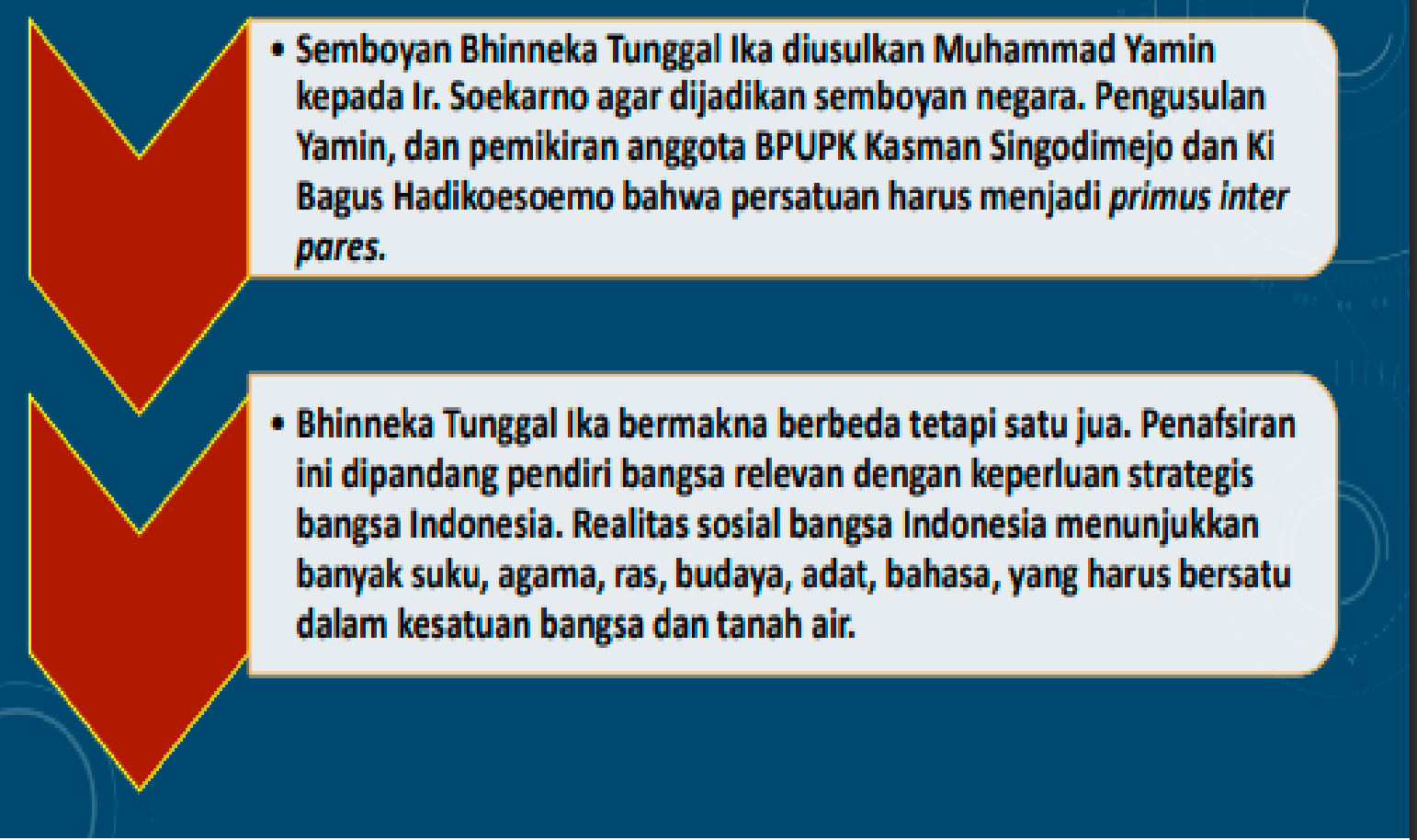

BHINNEKA TUNGGAL IKA

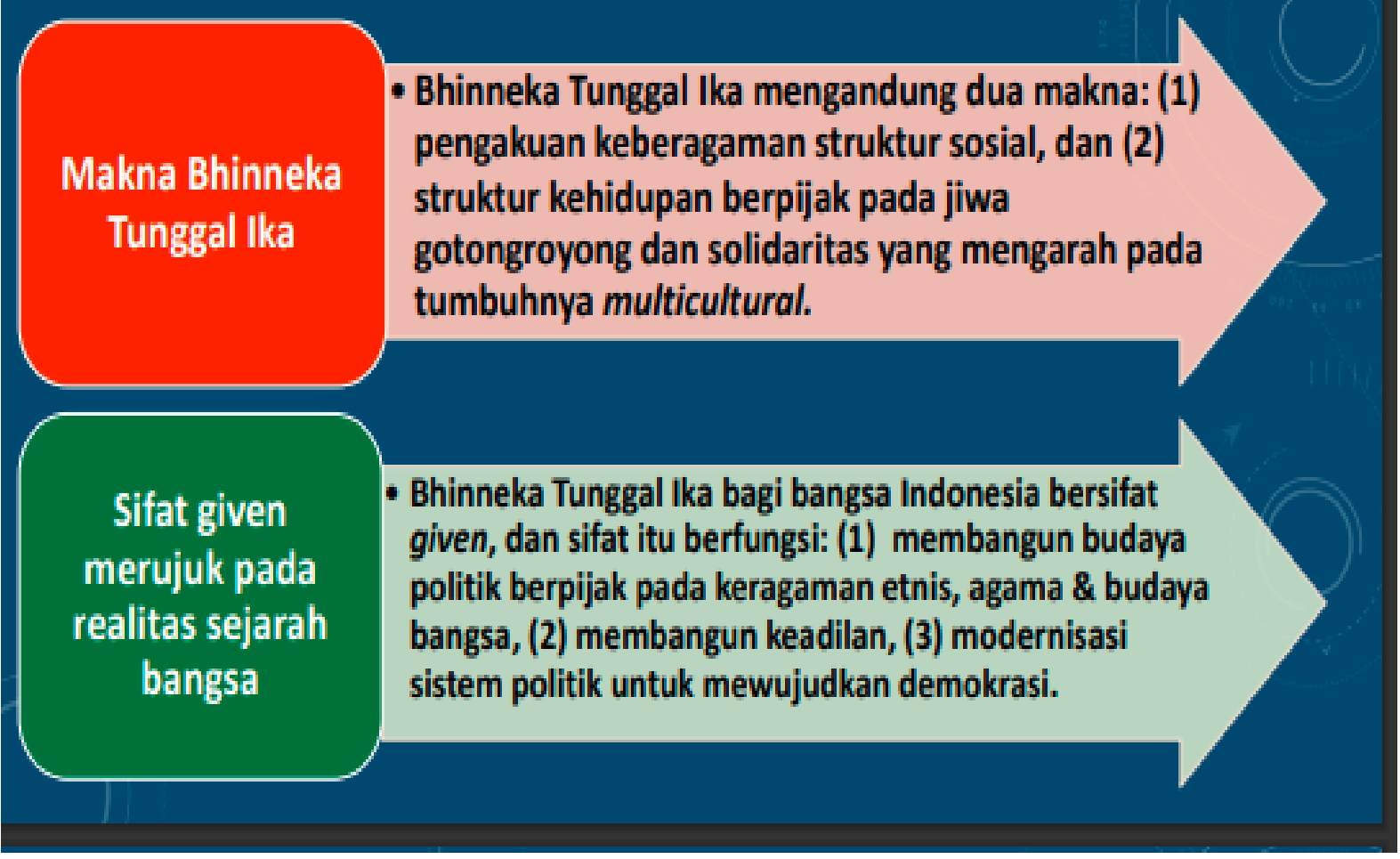




\section{BHINNEKA TUNGGAL IKA SEBAGAI SEMBOYAN NEGARA}

\begin{tabular}{|c|c|c|}
\hline KEANEKARAGAMAN & SUMPAH PEMUDA & $\begin{array}{c}\text { SEMBOYAN BHINNEKA } \\
\text { TUNGGAL IKA }\end{array}$ \\
\hline $\begin{array}{l}\text { 1. Bangsa yang majemuk } \\
\text { memiliki jumlah penduduk } \\
\text { yang cukup besar } \\
\text { 2.Memiliki bahasa daerah } \\
\text { yang berbeda beda } \\
\text { 3.Mempunyai suku bangsa } \\
\text { yang beragam } \\
\text { 4.Mempunyai agama yang } \\
\text { berbeda } \\
\text { 5.Warna kulit bermacam } \\
\text { macam } \\
\text { 6.Adat istiadat dan } \\
\text { 7.Banyak lagi perbedaaan } \\
\text { lainnya }\end{array}$ & $\begin{array}{l}\text { 1. Kami putra dan putri } \\
\text { Indonesia mengaku } \\
\text { bertumpah darah yang satu, } \\
\text { tanah air Indonesia } \\
\text { 2. Kami putra dan putri } \\
\text { Indonesia mengaku } \\
\text { berbangsa yang satu, bangsa } \\
\text { Indonesia } \\
\text { 3. Kami putra dan putri } \\
\text { Indonesia menjunjung } \\
\text { bahasa persatuan, bahasa } \\
\text { Indonesia. }\end{array}$ & $\begin{array}{l}\text { 1. Ikrar untuk bersatu padu } \\
\text { mendirikan Negara Kesatuan } \\
\text { Republik Indonesia } \\
\text { 2. Cita-cita membangun } \\
\text { sebuah bangsa Indonesia } \\
\text { yang bersatu } \\
\text { 3. Semboyan yang } \\
\text { mengungkapkan rasa } \\
\text { persatuan dan kesatuan } \\
\text { yang berasal dari } \\
\text { keanekaragaman. }\end{array}$ \\
\hline
\end{tabular}

\section{TOLERANSI PRIMUS INTER PARES DALAM PILAR BHINNEKA TUNGGALIKA}

\section{Soekarno memandang}

bhinneka tunggal ika

wujud persatuan bangsa

di dalamnya terkandung

nilai kemanusiaan dan

gotong royong untuk

menjamin

keberlangsungan bangsa Indonesia
Sifat bhinneka tunggal ika adalah pengelolaan toleransi antarsuku, agama, ras, dan golongan. Dewasa ini

toleransi menjadi suatu keniscayaan karena kuatnya ego sektoral kelompok agama dan politik

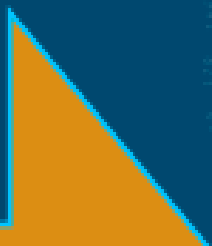

Douglas E. Ramage (1996) dan Acharya (2012) menafsirkan pandangan hidup masyarakat bangsa yang dituntun ideologi Pancasila mengarustamakan guyub rukun (damai), meski perbedaan itu bagian sunatullah 


\section{PEMINGGIRAN IDEOLOGI PANCASILA}

Ambruknya ideologi sosialisme, komunisme, kebangkitan Islam pada 1980 an, dan jatuhnya pemerintahan Orde Baru mendorong penggiran ideologi Pancasila. Bahkan gerakan mendirikan negara Islam begitu mencuat

\section{(4)}

Kebangkitan purifikasi agama menampilkan firqoh-firqoh baru yang timbulkan krisis identitas, antarmereka saling berhadapan untuk mendapatkan ruang public dan kekuasaan politik melalui instrumen agama

Akhirnya timbul konflik yang tidak menghargai perbedaan atau intoleran, serta mendorong mereka menggunakan tindakan radikal dan teror terhadap umat yang tidak sepaham

\section{RELIGIOUSITY OUR NATION STATE}
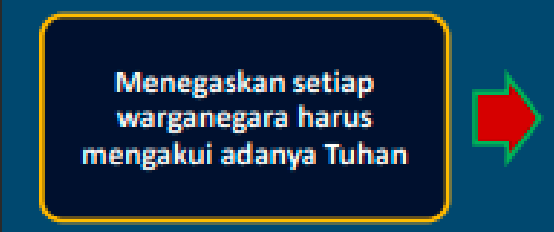
Indonesia bukan negara agama yang mempresentasikan agama tertentu
Negara harus menjamin tegaknya toleransi beragama yang berkeadaban

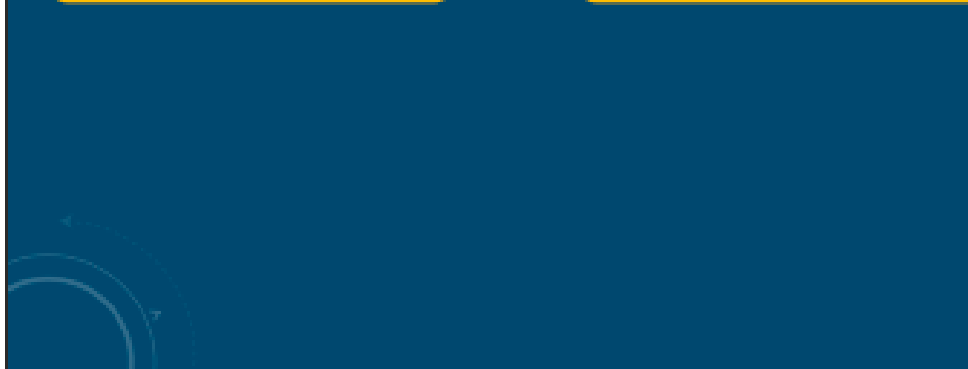
Indonesia bukan negara sekuler yang
memisahkan negara dan agama, dan
tidak berpretensi untuk menyudutkan
agama dalam ruang privat saja 


\section{GUYUB RUKUN SEBAGAI PERSONIFIKASI TOLERANSI}

Dalam masyarakat majemuk "guyub dan rukun" itu personifikasi damai, dan guyub dan rukun merupakan prinsip agama, yang di dalamnya terdapat nilai-nilai kemanusiaan.

- Sebuah kata "Allah al-Salam" dapat kita dimaknai bahwa Allah Mahadamai, dan dariNya kita semua sebagai umat dan makhluknya wajib mewujutkan dan menciptakan perdamaian, karena manusia sebagai makhluk mulia yang bisa menciptakan perdamaian tersebut.

\section{EMPAT PRINSIP DALAM KEBHINEKAAN DAN KEBANGSAAN}

Prinsip kesatuan dengan meletakkan loyalitas dan integritas setiap warganegara kepada bangsa dan negara

Prinsip kebebasan dengan memberi ruang warganegara mengembangkan kreativitas diri untuk kemajuan bangsa

Prinsip kesamaan, tidak membedakan atas dasar suku, agama, ras, dan aliran

Prinsip kepribadian menunjukkan perilaku keadaban menghormati dan menghargai umat ciptaan Tuhan 


\section{MODIFIKASI KEBHINNEKAAN DALAM NILAI, PRIBADI DAN DAYA SAING}

- Kehidupan berbhinneka itu mengutamakan toleransi, equality \&

NILAI equity, consciousness, loyality, teamwork, will to improve \& integrity

- Pribadi berbhinneka adalah sosok yang unselfishness (tidak egois), charity, cooperative, service behavior (mau melayani), dan

PRIBADI empowering the other melalui technical skill

- Menjadi daya saing bila digunakan sebagai system belief baik dalam DAYA SAING berkomunikasi, kerjasama, sinergi, dan berkompetisi secara sehat.

PANCASILASEBAGAI ENABLING ENVIRONMENT UNTUK MENENUN TOLERANSI DAN PERSATUAN

TERSEDIANYA RUANG PUBLIK UNTUK PELAJARI DAN PENGAMALAN PANCASILA :

PERTAMA, eksistensi 5 tempat ibadah sebagai modal sosial menumbuhkembangkan toleransi.

KEDUA, eksistensi Pusat Studi Pengamalan Pancasila dan Cofe Bhinneka sebagai co-working spoce, mengurai sekat dan menenun persatuan dan kebangsaan

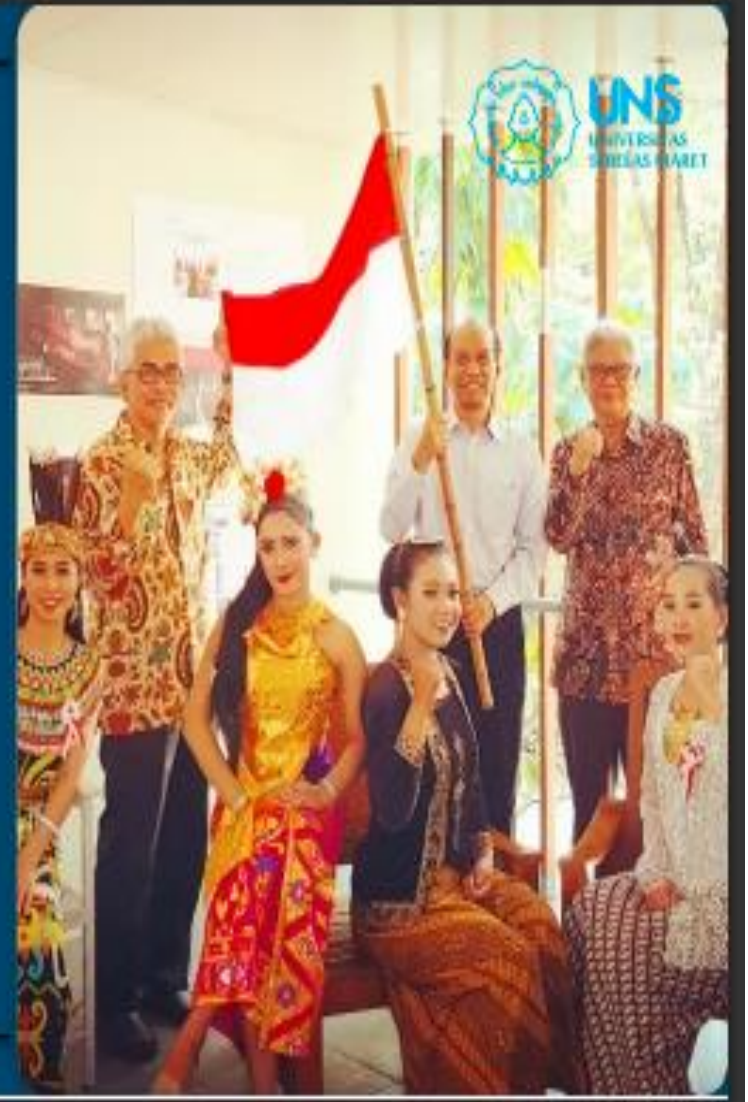




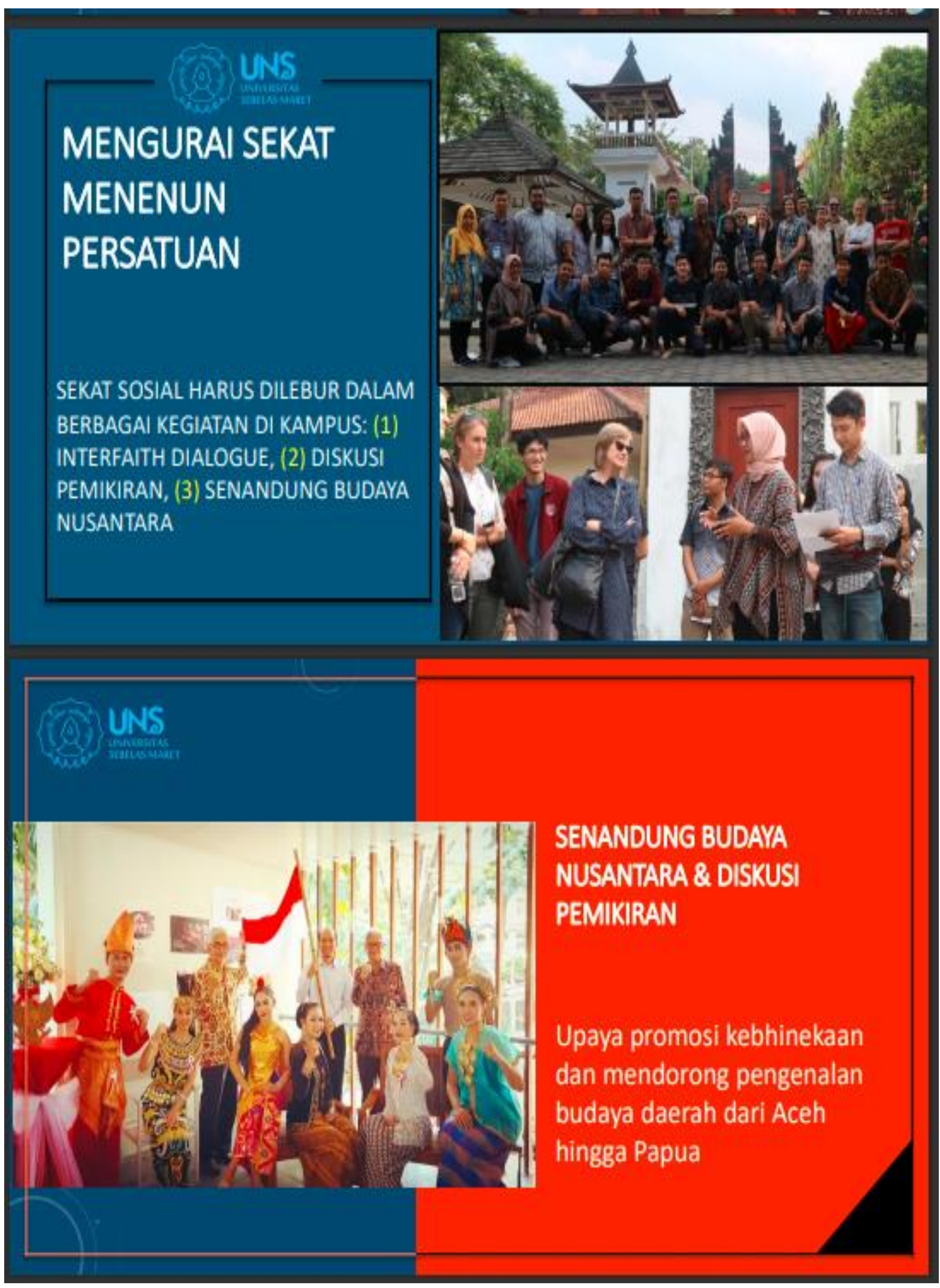

